\title{
In vitro antioxidant, collagenase inhibition, and in vivo anti-wrinkle effects of combined formulation containing Punica granatum, Ginkgo biloba, Ficus carica, and Morus alba fruits extract
}

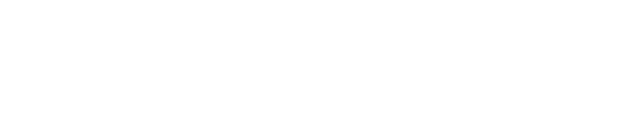

\author{
Amal Kumar Ghimeray' \\ Un Sun Jung ${ }^{1,2}$ \\ Ha Youn Lee' \\ Young Hoon Kim' \\ Eun Kyung Ryu' \\ Moon Sik Chang' \\ 'R\&D Center, Natural Solution \\ Co., Ltd, Gojan-dong, Namdong-gu, \\ Incheon, Republic of Korea; \\ ${ }^{2}$ Department of Horticultural \\ Biotechnology, Kyung Hee University, \\ Yongin, Republic of Korea
}

\begin{abstract}
Background: In phytotherapy, the therapeutic potential is based on the combined action of different herbal drugs. Our objective was to evaluate the antioxidant, anti-collagenase (in vitro), and anti-wrinkle (in vivo) effect of combined formulation containing Ginkgo biloba, Punica granatum, Ficus carica, and Morus alba fruits extract.
\end{abstract}

Methods: Antioxidant evaluation was based on the scavenging activity of free radicals (1,1-diphenyl-2-picrylhydrazyl, $\mathrm{H}_{2} \mathrm{O}_{2}$, and $\mathrm{O}_{2}^{-}$) and the anti-collagenase activity was based on the reduction of collagenase enzyme in vitro. In an in vivo study, 21 female subjects were examined in a placebo-controlled trail. Facial wrinkle, especially the crow's feet region of eyes, was treated with topical formulated $2 \%$ cream for 56 days and compared with the placebo.

Results: In the in vitro study, the combination of fruits extract showed a higher antioxidant activity which was comparable with the positive standard (ascorbic acid, butylated hydroxyanisole, and Trolox). The data also showed a dose-dependent inhibition of collagenase. In the in vivo study, treatment with $2 \%$ formulated cream for 56 days significantly reduced the percentage of wrinkle depth, length, and area with $11.5,10.07$, and 29.55, respectively.

Conclusion: The combined formulation of fruit extracts showed excellent antioxidative and anti-collagenase activity as well as a significant effect on anti-wrinkle activity on human skin.

Keywords: antioxidant, anti-collagenase, anti-wrinkle, fruits, topical formulation

\section{Introduction}

Plant extracts rich in phytochemicals such as flavonoids, phenolic acids, tocopherols, alkaloids, and monoterpenes, having antioxidant or anti-inflammatory activity, are being widely used for the development of topical cosmetic products. ${ }^{1}$ Recently in market, an increased number of pharmaceutical or cosmetic products with the combination of several herbal extracts have been introduced. It is found that the multiple combinations of plants extract have shown higher phytotherapy efficacy compared with the products with single extracts.,3 For instance, clinical evidences of synergy effects of Valeriana officinalis + Humulus lupulus, V. officinalis + Kava-kava, Urtica dioica + Pygeum africanum, Ginseng + Ginkgo always showed higher efficacy than their single extract. ${ }^{4}$ Likewise, extracts of Hypericum perforatum, Sabal serrulata, Hedera helix, and Boswellia serrata also showed better therapeutic efficacy than that of the synthetic drugs (standard) used in the clinical studies. ${ }^{3}$ Other studies have shown the pharmaceutical superiority of the extracts over the isolated compounds. For example, Valeriana extract ( $V$. officinalis), Zingiber extract (Zingiber officinalis), Ginkgo extract
Correspondence: Moon Sik Chang R\&D Center, Natural Solution Co., Ltd, I58B I IL, \#504, 730-I0, Gojan-dong, Namdong-gu, Incheon, 23050, Republic of Korea

Tel +82328120530

$\mathrm{Fax}+82328120531$

Email justin0510@naturalsolution.co.kr 
(Ginkgo biloba), Piper methysticum extract, and Licorice extract (Glycyrrhiza glabra) showed higher efficacy than that of its individual constituents. ${ }^{4}$

The present investigation has been carried out on four different plants (Punica granatum, Ficus carica, Morus $a l b a$, and $G$. biloba) fruit extracts whose individual pharmaceutical efficacy has already been understood. For instance, P. granatum fruit (Punicaceae family) extract is widely used in therapeutics, cosmetics, and food seasonings. The fruit extract showed its protective and chemopreventive properties in human skin fibroblasts against ultraviolet- (UVA and UVB) induced damage. ${ }^{5}$ The extract also have efficacy to inhibit matrix metalloproteinase (MMP)-1 produced by dermal fibroblasts. ${ }^{6}$

Morus alba (Moraceae family) fruit contain a higher amount of polyphenols, phytosterols, anthocyanins, saponins, triterpenes, amino acids, fatty acids, and minerals. ${ }^{7}$ It is also rich in flavonoid compounds such as rutin, kaempferol, quercetin, and scopolitin. M. alba proved its efficacy in neuroprotective, immunomodulatory, anticancer, antimicrobial, and antioxidant activities. ${ }^{8}$ Likewise, another fruit from the same Moraceae family, F. carica, contains numerous phenolics (ferulic, caffeoyl quinic acid, and quercetin glycosides) and organic acids (malic, citric, fumaric, oxalic, quinic, shikimic, and chlorogenic acids). The fruit extract showed its efficacy in antioxidant, anti-inflammatory, anti-ulcerogenic, hepatoprotective, and gastroprotective activities. ${ }^{9}$

Ginkgo biloba (Ginkgoaceae family) contains different phytoactive compounds such as flavonoids, terpene trilactones, proanthocyanidins, ginkgolic acids, biflavone, and ginkgotoxins. Ginkgo fruits and seed are also used traditionally against various diseases such as asthma, cough, and enuresis..$^{10}$ The Ginkgo fruits (nuts) are also known to have health benefits for prevention of cancer, cardiovascular, neurological disorder, and photoprotective effect. ${ }^{11,12}$

Collagenase enzyme is a metalloproteinase which can degrade molecules such as aggrecan, elastin, fibronectin, gelatine, laminin, and collagen. ${ }^{13}$ Therefore, the agents that inhibit collagenase activity may have beneficial effects to maintain healthy skin by preventing dermal matrix degradation. Here, we investigated the inhibitory activity of combined fruits formulation against collagenase enzyme to elucidate their therapeutic potential against anti-wrinkle activity. In this study, our main objective was to evaluate the antioxidant, anti-collagenase (in vitro), and anti-wrinkle (in vivo) effect of fruit's extract of four different plant species in combination.

\section{Materials and methods}

\section{Sample preparation}

The ripened fruits of P. granatum, G. biloba, F. carica, and M. alba were purchased from the local market in their available season in the year 2011. After collection, the samples were air dried (moisture free), grinded to powder, and stored in a refrigerator till used. The air-dried fruit sample (100 g each) was extracted using $70 \%$ ethanol at room temperature. The extracts were evaporated in a rotatory evaporator at $40^{\circ} \mathrm{C}$. The extracted powder samples were combined in equal proportion and used for experiment after dilution for antioxidant and collagenase inhibition activity in vitro.

\section{Topical formulation of fruits extract}

Two percent of combined fruit extracts (P. granatum, F. carica, M. alba, and G. biloba) were mixed with a formulation containing water, carbomer, glycerine, disodium EDTA (ethylenediaminetetraacetic acid), methyl paraben, triethanolamine, tocopheryl acetate, polysorbate 60 , stearyl alcohol, PEG-100 (polyethylene glycol-100) stearate, sorbitan stearate, caprylic/capric triglyceride, dimethicone, mineral oil, propylparaben, butylene glycol, beeswax, and fragrance. The placebo (control) was identical in composition, except fruits extract.

\section{In vitro antioxidant activity DPPH free radical scavenging assay}

The antioxidant activity of extract on the basis of the scavenging activity of the stable 1,1-diphenyl-2-picrylhydrazyl (DPPH) free radical was determined according to the method described by Braca et al, ${ }^{14}$ with a slight modification. Briefly, a dilution series (three different concentrations) of formulated extract was prepared in a 96-well plate. The reaction mixture consisted of $0.1 \mathrm{~mL}$ extract with $0.2 \mathrm{~mL}$ DPPH solution ( $0.15 \mathrm{mM}$ in $80 \%$ methanol solution). The mixture was shaken vigorously and left to stand for 30 minutes at room temperature in the dark. Ascorbic acid was taken as positive control. The absorbance of the resulting solution was measured spectrophotometrically at $517 \mathrm{~nm}$ and the percent inhibition activity was calculated according to following formula:

$$
\text { Scavenging activity }(\%)=\left(\mathrm{A}_{\text {control }}-\mathrm{A}_{\text {sample }}\right) / \mathrm{A}_{\text {control }} \times 100
$$

where $\mathrm{A}_{\text {control }}$ is the absorbance of the control reaction and $\mathrm{A}_{\text {sample }}$ is the absorbance in the presence of extract.

\section{$\mathrm{H}_{2} \mathrm{O}_{2}$ scavenging inhibition activity}

The scavenging activity of $\mathrm{H}_{2} \mathrm{O}_{2}$ was performed according to the protocol of Sroka and Cisowski. ${ }^{15}$ Briefly, sample 
extract $(100 \mu \mathrm{L})$ was diluted in different concentrations. To the sample, $\mathrm{H}_{2} \mathrm{O}_{2}(100 \mu \mathrm{L}), 0.1 \mathrm{M} \mathrm{NaCl}(100 \mu \mathrm{L})$, and $0.1 \mathrm{M}$ phosphate buffer $(700 \mu \mathrm{L}, \mathrm{pH}, 7.0)$ were mixed thoroughly and incubated at $37^{\circ} \mathrm{C}$ for 20 minutes. Furthermore, $1 \mathrm{~mL}$ of a solution containing phenol red $(0.2 \mathrm{~g} / \mathrm{mL})$ and horseradish peroxidase $(0.1 \mathrm{mg} / \mathrm{mL})$ was added and mixed thoroughly before incubated at $37^{\circ} \mathrm{C}$ for 15 minutes. The absorbance was taken at $610 \mathrm{~nm}$ against a blank after the addition of 1 $\mathrm{M} \mathrm{NaOH}(100 \mu \mathrm{L})$ to the incubated solution. The percentage of inhibition was calculated according to the following formula:

Percentage inhibition $\left(\mathrm{H}_{2} \mathrm{O}_{2}\right)=\mathrm{A}_{\text {control }}-\mathrm{A}_{\text {sample }} / \mathrm{A}_{\text {control }} \times 100$

where $\mathrm{A}_{\text {control }}$ refers to the control solution without sample (only water) and $A_{\text {sample }}$ refers to the absorbance with the sample.

\section{Superoxide inhibition activity}

The superoxide anion $\left(\mathrm{O}_{2}^{-}\right)$scavenging activity was measured according to the method of Nishimiki et al. ${ }^{16}$ Briefly, different concentrations of sample $(1 \mathrm{~mL})$ were mixed with nitro blue tetrazolium solution $(156 \mu \mathrm{M}$ in $100 \mathrm{mM}$ phosphate buffer, $\mathrm{pH}$ 7.4) and $1 \mathrm{~mL}$ nicotinamide adenine dinucleotide (468 $\mu \mathrm{M}$ in $100 \mathrm{mM}$ phosphate buffer, $\mathrm{pH}$ 7.4). The reaction was initiated by adding $100 \mu \mathrm{L}$ of phenazine methosulfate (prepared with $100 \mu \mathrm{M}$ phosphate). The mixture was incubated at $25^{\circ} \mathrm{C}$ for 5 minutes and the absorbance was measured at $560 \mathrm{~nm}$ against blank samples. The percentage inhibition of superoxide radical was calculated using the following formula:

$$
\%=\left(\mathrm{A}_{\text {blank }}-\mathrm{A}_{\text {sample }}\right) / \mathrm{A}_{\text {blank }} \times 100
$$

where $\mathrm{A}_{\text {blank }}$ is the absorbance of the control reaction (without test sample) and $\mathrm{A}_{\text {sample }}$ is the absorbance of the extracts.

\section{Collagenase inhibition activity}

Collagenase inhibition activity was performed according to the protocol of Barrantes and Guinea ${ }^{17}$ with a slight modification. Briefly, a dilution series (different concentrations of $0.5 \%, 1 \%, 2.5 \%$, and $5 \%$ ) of extract $(50 \mu \mathrm{L})$ was prepared in a 96-well plate were mixed with $20 \mu \mathrm{L}$ of type-I collagen (substrate). Then, a diluted collagenase enzyme $(100 \mu \mathrm{L}, 0.2 \mathrm{U} \mathrm{mL})$ was added to each well and the reaction mixtures were incubated for 30 minutes at $37^{\circ} \mathrm{C}$. The final volume was adjusted to $200 \mu \mathrm{L}$ with $30 \mu \mathrm{L}$ of buffer. Negative control was performed with buffer and substrate but without enzyme. Fluorescence was measured at excita- tion maxima of $495 \mathrm{~nm}$ and emission maxima of $515 \mathrm{~nm}$. All assays were performed independently in triplicates. The inhibition percentage was calculated according to the following formula:

$$
\begin{aligned}
& \text { Collagenase inhibition activity }(\%) \\
& =\left(1-\mathrm{S}_{\mathrm{abs}}-\mathrm{Sb}_{\mathrm{abs}} / \mathrm{C}_{\mathrm{abs}}-\mathrm{Cb}_{\mathrm{abs}}\right) \times 100
\end{aligned}
$$

where $\mathrm{S}$ is the sample test absorbance, $\mathrm{Sb}$ is the sample blank absorbance, $\mathrm{C}$ is the positive control absorbance, $\mathrm{Cb}$ is the negative control absorbance.

\section{Human clinical study (wrinkle area difference, length, depth, and dermatological (visual) score)}

The study was proposed during October 15, 2012 to January 15, 2013 in Guangzhou city, Land Proof Test Technology Co, Ltd, People's Republic of China. This study was a randomized, open, single-blinded, placebo-controlled, observer-blinded study which was approved by GuangDong light industry association institutional review committee for human testing. Twenty-one female subjects aged $45-65$ years (without the history of serious diseases or allergic to cosmetics or pregnant women) participated in the study. The subjects' crow's feet area on both sides (right and left) were selected in which the wrinkles must not cross each other and the length of the main wrinkle must be at least $2 \mathrm{~cm}$ long. All subjects gave a written informed consent prior to the study and evaluated for tolerance. Subjects were treated with $2 \%$ topical formulated fruit extract on one side of the face (crow's feet) and with placebo (ingredients without fruit extract) on the other side twice a day for 58 days. Clinical evaluations and measurements were performed on D0 (before treatment), D28, and D56. The effect of extracts on wrinkle was evaluated by using Cutometer MPA 580 (Courage and Khazaka Electronic, Köln, Germany), which measures skin elasticity, Visioline VL650 (Courage and Khazaka Electronic), which measures wrinkle depth, and SILFLO kit (cuDerm corporation, Dallas, TX, USA). Prior to visual score (dermatological score) by dermatologist, subjects were acclimatized under a standard laboratory condition (temperature $22^{\circ} \mathrm{C} \pm 1^{\circ} \mathrm{C}$ and humidity $50 \pm 3$ ).

\section{Statistical analysis}

Statistical analyses were carried out using the SPSS software (version 11.5; SPSS Inc., Chicago, IL, USA). The differences among samples were statistically evaluated via one-way analysis of variance followed by Dunnett's post hoc test or 
Wilcoxon's test when appropriate. The level of significance was set at $P<0.05, P<0.01$, and $P<0.001$. Data are expressed as mean \pm standard error.

\section{Result}

\section{In vitro antioxidant activity}

Ethanolic extracts of four different types of fruits (P. granatum, G. biloba, F. carica, and M. alba) in combined form showed a different pattern of antioxidant activity. The antioxidant efficacy of combined fruit extract in comparison with control (standard compounds) is given in Table 1. The extract showed a higher free radical (DPPH) scavenging activity with the $\mathrm{IC}_{50}$ value of $4.24 \pm 1.84 \mu \mathrm{g} / \mathrm{mL}$. This value was very close to ascorbic acid (positive control) used in the experiment, which shows the $\mathrm{IC}_{50}$ value of $2.26 \pm 0.67$ $\mu \mathrm{g} / \mathrm{mL}$. In the hydrogen peroxidation inhibition assay, the extract showed the $\mathrm{IC}_{50}$ value of $35.14 \pm 2.58 \mu \mathrm{g} / \mathrm{mL}$ and the BHA (positive control) showed the $\mathrm{IC}_{50}$ value of $24.69 \pm 0.87 \mu \mathrm{g} / \mathrm{mL}$. In the superoxide inhibition assay, the fruit extract inhibited oxygen radical in a dose-dependent manner. The $\mathrm{IC}_{50}$ value of fruit extract was $4.97 \pm 1.02 \mathrm{com}-$ pared to Trolox (positive control) used in the experiment with the value of $27.23 \pm 1.05 \mu \mathrm{g} / \mathrm{mL}$.

\section{Collagenase inhibition activity}

Figure 1 shows the dose-dependent inhibition of enzymes by the combined fruit extract. The incubation of the enzyme with the fruit extract significantly $(P<0.05)$ inhibited the enzyme. A concentration of $5 \mu \mathrm{g} / \mathrm{mL}$ extract showed $67.45 \%$ enzyme inhibition, whereas lower concentrations of $0.5,1$, and $2.5 \mu \mathrm{g} / \mathrm{mL}$ fruit extract caused $12.03 \%, 32.90 \%$, and $55.61 \%$ enzyme inhibition, respectively.

\section{Human clinical study}

We examined the effect of $2 \%$ topical formulated fruit cream on the wrinkles of crow's feet site of the eyes (Figure 2). The

Table I In vitro antioxidant activity of fruits extract

\begin{tabular}{llll}
\hline $\mathrm{IC}_{50}$ value \pm mean $(\mathrm{SD})^{\mathrm{a}}(\boldsymbol{\mu g} / \mathrm{mL})$ & & \\
\hline Extract/compound & DPPH & $\begin{array}{l}\text { Hydrogen } \\
\text { peroxidation }\end{array}$ & Superoxide \\
\hline Sample (fruits) extract & $4.24 \pm 1.84$ & $35.14 \pm 2.58$ & $4.97 \pm 1.02$ \\
Standards & & & - \\
Ascorbic acid & $2.26 \pm 0.67$ & - & $27.23 \pm 1.05$ \\
Trolox & - & - & - \\
BHA & - & $24.69 \pm 0.87$ & \\
\hline
\end{tabular}

Notes: Standard compounds ascorbic acid, BHA, and Trolox were used for comparison. ${ }^{a}$ Average of three determinations.

Abbreviations: SD, standard deviation; DPPH, I, I-diphenyl-2-picrylhydrazyl; BHA, butylated hydroxyanisole.

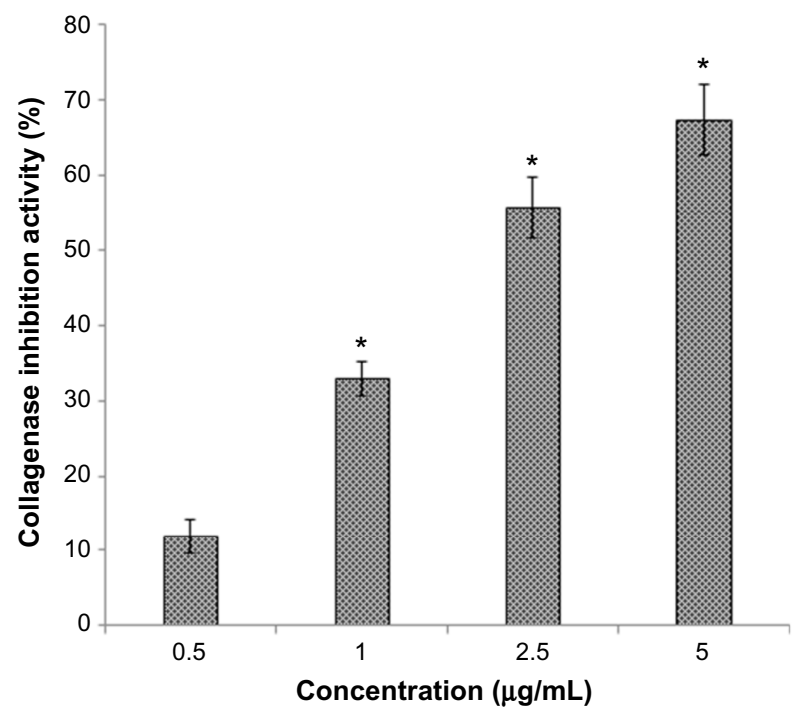

Figure I Dose-dependent inhibition of collagenase by combined fruits extract. Fluorescence was measured at excitation maxima of $495 \mathrm{~nm}$ and emission maxima of $515 \mathrm{~nm}$. The data are representative of three different experiments with similar results. $* P<0.05$ when compared with placebo.

wrinkle area, depth, and length at the baseline were analyzed to identify the differences at sample treated sites. Treatment with $2 \%$ formulated cream for 28 days did not show any significant difference with the placebo. However, treatment for 56 days reduced significantly the percentage of wrinkle depth (Figure 3), length (Figure 4), and area (Figure 5) by $11.5 \%, 10.07 \%$, and $29.55 \%$, respectively, compared with the placebo. The dermatological scores of the sides treated by the extract containing cream decreased significantly $(P<0.05)$ on 56 days with 1.5 fold lower than that of the placebo treatment (Figure 6).

\section{Discussion}

The efficacy of individual plants (P. granatum, G. biloba, F. carica, and M. alba) extract on pharmaceutical application have been evaluated elsewhere. ${ }^{8,9,18}$ According to our data, the combined fruit's extract showed a higher antioxidant activity in vitro DPPH, $\mathrm{H}_{2} \mathrm{O}_{2}$, and $\mathrm{O}_{2}^{-}$model, which was comparable with the positive standard (ascorbic acid, BHA, and Trolox) used in the experiment (Table 1).

According to the published literatures elsewhere, it has been known that the P. granatum fruit (both seed and pills) exhibits a higher antioxidant activity due to the presence of different phenolic compositions such as anthocyanins, punicalagin isomers, and elagic acid. ${ }^{19}$ Singh et al ${ }^{20}$ reported that the peels and seeds of $P$. granatum scavenge DPPH free radicals with $81.0 \%$ and $23.2 \%$ at 50 and $100 \mu \mathrm{g} / \mathrm{mL}$ concentrations of methanolic extract, respectively. The author also reported $51.0 \%$ of hydroxyl scavenging activity of the fruit at a concentration of $100 \mu \mathrm{g} / \mathrm{mL}$. 


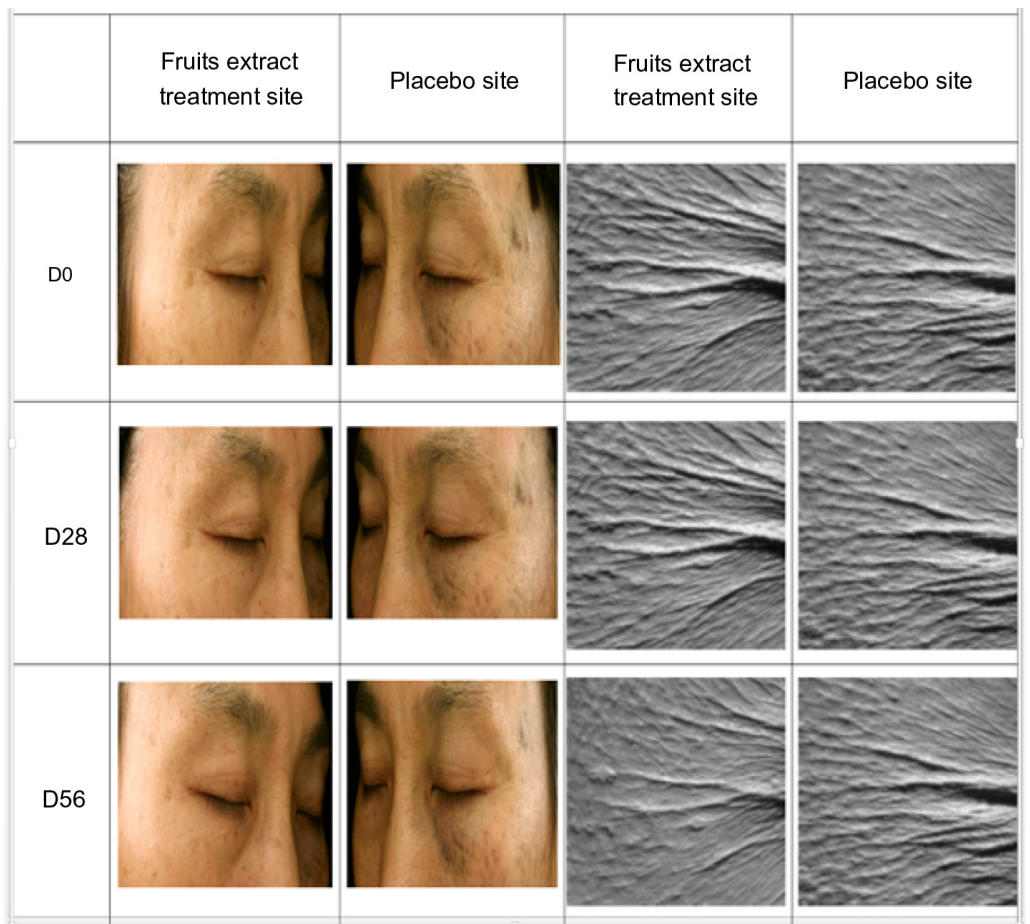

Figure 2 Photograph showing the images of wrinkles used for assessment of wrinkle area, depth, and length in the crow's feet region of subject's eyes treated with $2 \%$ topically formulated fruits extract and placebo treated for 56 days. Clinical evaluations and measurements were performed on D0 (before treatment), D28, and D56. Abbreviation: D, day.

Morus alba is rich in polyphenolic compounds especially the flavonoids and among the flavonoids quercetin 3,6-malonyglycoside is the most significant component accounting for the antioxidant potential of mulberry plant. ${ }^{21}$ Moreover, anthocyanin components such as cyanidin-3-glucoside,

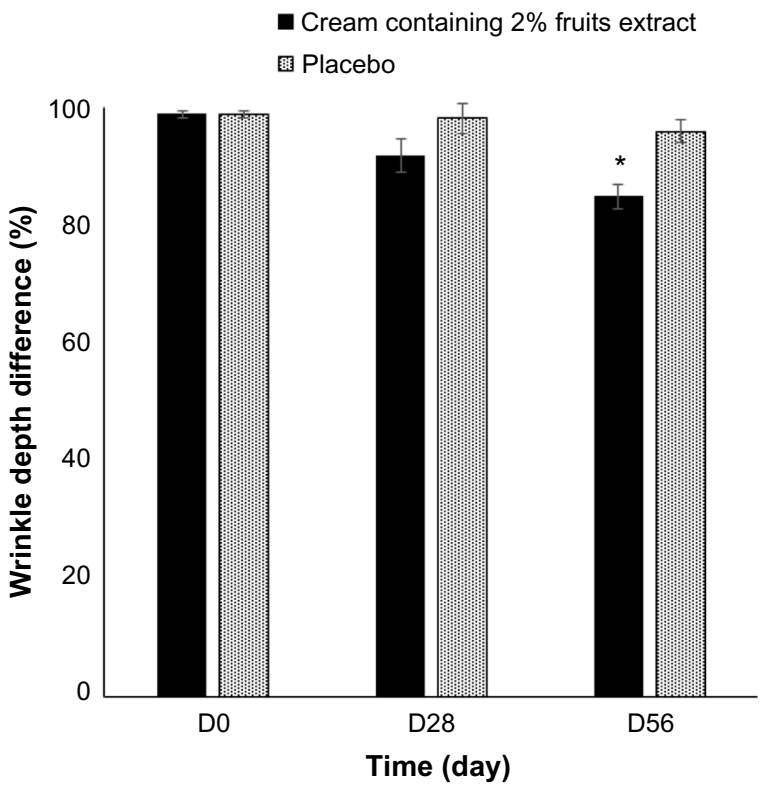

Figure 3 Differences in the wrinkle depth after the treatment of $2 \%$ topical formulated fruit extracts containing cream or the placebo randomly on crow's feet region of eyes of 21 healthy subjects. Data are expressed as mean $\pm \mathrm{SE}$. $* P<0.05$ when compared with placebo. cyanidin-3-rutinoside, and stilbene glycoside (mulberroside A) also attribute to the antioxidant activity of $M$. alba. ${ }^{22}$ According to the report by Khan et al, ${ }^{23}$ the $\mathrm{IC}_{50}$ value of $M$. alba in the DPPH model was $76.0 \mu \mathrm{g} / \mathrm{mL}$ and the standard (catechin) used in the experiment showed the $\mathrm{IC}_{50}$ value

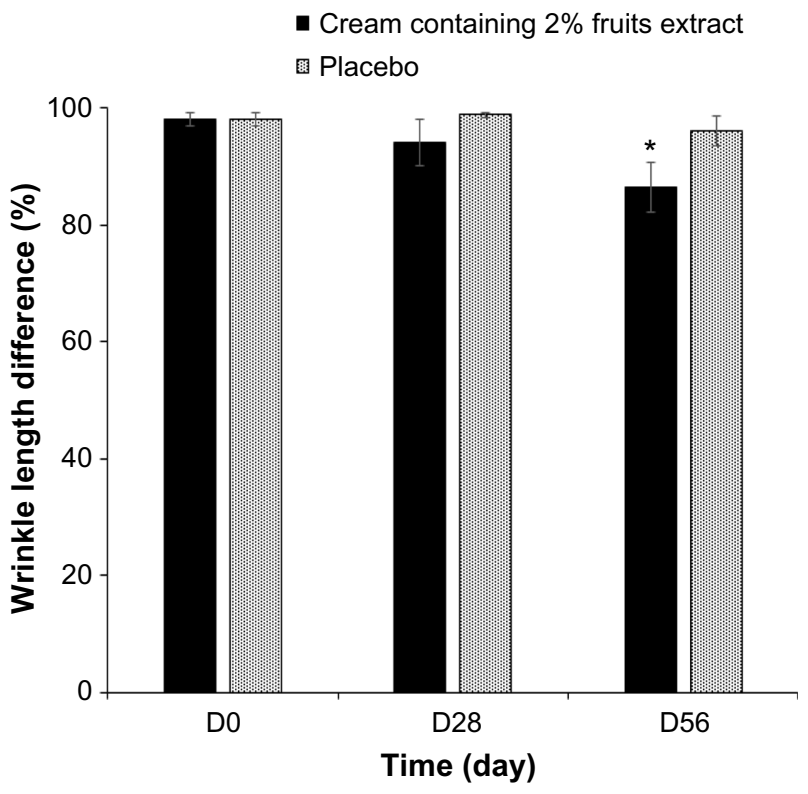

Figure 4 Differences in the wrinkle length after the treatment of $2 \%$ topical formulated fruit extracts containing cream or the placebo randomly on crow's feet region of eyes of 21 healthy subjects. Data are expressed as mean \pm SE. $* P<0.05$ when compared with placebo. 


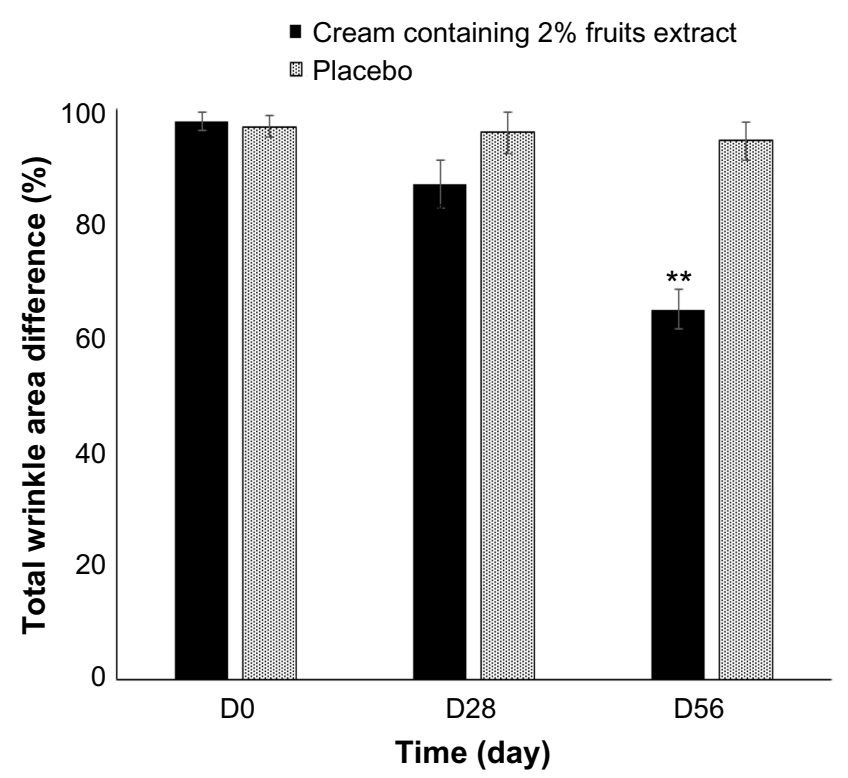

Figure 5 Differences in the wrinkle area after the treatment of $2 \%$ topical formulated fruits extract containing cream or the placebo randomly on crow's feet region of eyes of 21 healthy subjects. Data are expressed as mean $\pm S E$. $* * P<0.01$ when compared with placebo.

of $27.5 \mu \mathrm{g} / \mathrm{mL}$. The author also compared the hydroxyl radial scavenging activity of the sample and the standard (BHT), which showed the $\mathrm{IC}_{50}$ value of 177.5 and $8.5 \mu \mathrm{g} /$ $\mathrm{mL}$, respectively.

Ficus carica fruit is characterized by the presence of higher quantities of phenolic acids and has significant antioxidant and anti-inflammatory properties. ${ }^{9}$ Due to the presence

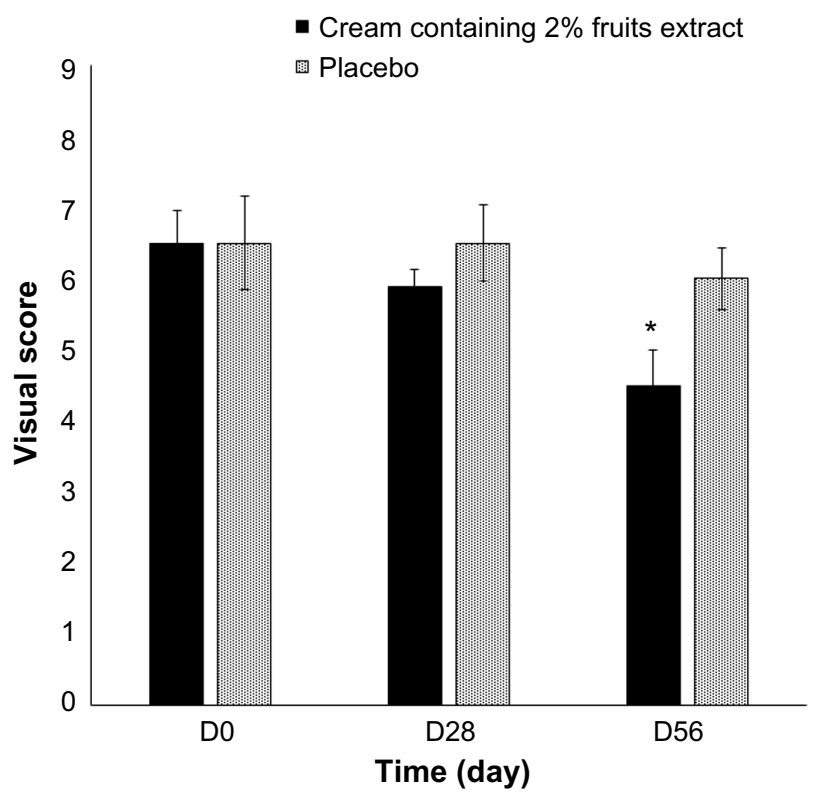

Figure 6 Differences in the visual score after the treatment of $2 \%$ topically formulated fruits extract containing cream or the placebo randomly on the crow's feet region of eyes of healthy subjects. Data are expressed as mean $\pm \mathrm{SE}$. $* P<0.05$ when compared with placebo. of phenolic acids such as chlorogenic acid, quercetin-3-0rutinoside (peels), and psoralen (pulp), Ficus fruits are utilized for the treatment of skin depigmentation. ${ }^{24}$ Yang et al ${ }^{25}$ reported that the methanolic extract of $F$. carica fruit showed the $\mathrm{IC}_{50}$ value of $80.0 \mu \mathrm{g} / \mathrm{mL}$, whereas the water extract of fruit showed the $\mathrm{IC}_{50}$ value of $720.0 \mu \mathrm{g} / \mathrm{mL}$ in the DPPH model. Similarly, the water extract of the fruit also showed a moderate superoxide radical scavenging activity with the $\mathrm{IC}_{50}$ value of $950.0 \mu \mathrm{g} / \mathrm{mL}$.

Ginkgo biloba extracts rich in flavonoid biflavones and terpene trilactones have been used widely due to the antiinflammatory effect. In an experiment, Jain et a ${ }^{26}$ reported that the methanol extract of $P$. granatum alone has the $\mathrm{IC}_{50}$ value of $147.6 \mathrm{mg} / \mathrm{mL}$ and that of G. biloba was $134 \mathrm{mg} / \mathrm{mL}$ in the DPPH model. In the superoxide scavenging activity assay, the $\mathrm{IC}_{50}$ value of P. granatum and G. biloba was 121.1 and $128.2 \mathrm{mg} / \mathrm{mL}$, respectively. However, in combined formulation, due to the synergistic effects, the $\mathrm{IC}_{50}$ values were increased to 33.5 and $46.39 \mathrm{mg} / \mathrm{mL}$ in DPPH and superoxide scavenging model system, respectively.

According to our data, the combined formulated fruit extract showed a much higher rate of inhibition (DPPH and hydroxyl radical scavenging assays) than the aforementioned efficacy of individual plant's fruit extract (Table 1). In the superoxide inhibition assay, the combined fruit extract showed 5.48-fold higher efficacy than that of Trolox. These higher inhibition activities of the combined formulated fruit extract could be due to the synergistic effect of phytochemicals present in the sample. According to Wagner, ${ }^{3}$ the higher efficacy of multidrug combination could be due to the increase in the solubility or resorption rate of one of the major constituents present in the extract, or could be due to the antagonistic effects of certain constituents against some toxic compounds.

It has been reported that collagenase cleaves the amino acid bond of collagen and breaks down the collagen and elastin which possibly leads to the prolonged skin damage or wrinkle formation. ${ }^{27}$ To prevent the skin from aging or wrinkles, natural collagenase inhibitors from plant is desirable. Naturally, plant phenolic compounds have been known to inhibit the collagenase activity. In previous findings, it has been reported that the butanol fraction of G. biloba seed, P. granatum (fruit), and M. alba (whole plant extract) inhibited up to $50.8 \%, 4.4 \%$, and $19.5 \%$ of MMP-9. ${ }^{28}$ Boiled water extract of $P$. granatum fruit exhibited both the collagenase (11\%) and elastase (14.64\%) inhibition activity. ${ }^{29}$ According to our research, the combined formulation of fruits exhibited comparatively higher inhibition 
of collagenase (shown in a dose-dependent manner in Figure 1). A concentration of $5 \mu \mathrm{g} / \mathrm{mL}$ fruit extracts showed $67.45 \%$ enzyme inhibition. This higher activity of collagenase inhibition by combined fruits may be due to the conformational change in collagenase induced by the synergistic effect of polyphenols. ${ }^{30}$

We examined a human in vivo clinical study focusing on the reduction of wrinkle (area, depth, and length) located around the eyes in crow's feet region (Figure 2). According to the data, the significant $(P<0.05, P<0.01)$ reduction of wrinkle (depth, length, and area) was observed after 56 days of application. Our in vivo data are based on observation; therefore, further molecular work is needed to understand the proper mechanism of anti-wrinkle activity of topically formulated fruit extract. According to the literature elsewhere, it is known that the reactive oxygen species directly act on fibroblasts and then reduce collagen production. ${ }^{31}$ Therefore, it can be speculated that the anti-wrinkle activity of fruit extract could be due to the presence of higher radical scavenging activity which quench the free radicals from the skin and thereby protect the collagen from degradation. And also, the phytochemical may have possible interactions with the special enzymes, mediators in the signal transduction pathway. ${ }^{3}$ For example, the anti-wrinkle activity of formulated fruit extract may be due to the suppressive effect of some phytochemicals on C-Jun N-terminal kinase or MMPs (MMP-1, MMP-3, and MMP-9) which activates due to oxidative stress. ${ }^{32}$

In conclusion, the combined formulation of $P$. granatum, G. biloba, F. carica, and M. alba fruits extract provides excellent antioxidative and anti-collagenase activity in vitro and also showed a significant effect on the anti-wrinkle activity in vivo. Overall, the results obtained in this research contributed to elucidate the possible effects on the anti-wrinkle prospects of skin with combined topical formulation of plant fruits extract.

\section{Acknowledgments}

The authors gratefully acknowledge W Lai (MD), ZY Zhong (MD), and YQ Zhang (MD) of Skin Research Center of Guangzhou Landproof and Department of Dermatology, The Third Affiliated Hospital of Sun Yat-Sen University, Guanhzhou, Guangdong Province, People's Republic of China, for conducting the in vivo research work. This study was funded by Natural Solution Co, Ltd, Republic of Korea.

\section{Disclosure}

The authors report no conflicts of interest in this work.

\section{References}

1. Verschooten L, Claerhout S, Van Laethem A, Agostinis P, Garmyn M. New strategies of photoprotection. Photochem Photobiol. 2006;82: 1016-1023.

2. Berenbaum M. What is synergy? Pharmacol Rev. 1989;41:93-141.

3. Wagner H. Multitarget therapy - the future of treatment for more than just functional dyspepsia. Phytomedicine. 2006;13(5):122-129.

4. Williamson EM. Synergy and other interactions in phytomedicine. Phytomedicine. 2001;8:401-409.

5. Pacheo-Palencia LA, Noratto G, Hingorani L, Talcott ST, MertensTalcott SU. Protective effects of standardized pomegranate (Punica granatum $\mathrm{L}$ ) polyphenolic extract in ultraviolet-irradiated human skin fibroblasts. J Agric Food Chem. 2008;56:8434-8441.

6. Aslam MN, Lansky EP, Varani J. Pomegranate as a cosmeceutical source: pomegranate fractions promote proliferation and procollagen synthesis and inhibit matrix metalloproteinase-1 production in human skin cells. J Ethnopharmacol. 2006;103:311-318.

7. Ercisli S, Orhan E. Chemical composition of white (Morus alba), red (Morus rubra) and black (Morus nigra) mulberry fruits. Food Chem. 2007;103:1380-1384.

8. Zafar MS, Faqir M, Ijaz J, et al. White Mulberry (Morus alba): a brief phytochemical and pharmacological evaluation account. Int J Agri Biol. 2013;15:612-620.

9. Sirisha N, Sreenivasulu M, Sangeeta K, Madhusudhana Chetty C. Antioxidant properties of Ficus species - a review. Int J Pharm Tech Res. 2010;2(4):2174-2182.

10. Mahady GB. Ginkgo biloba: a review of quality, safety, and efficacy. Nutr Clin Care. 2001;4:140-147.

11. Goh LM, Barlow PJ. Antioxidant capacity in Ginkgo biloba. Food Res Int. 2002;35:815-820.

12. Belo SED, Lorena RG, Parica MBGMC. Photoprotective effects of topical formulations containing a combination of Ginkgo biloba and green tea extracts. Phyto Res. 2011;25:1854-1860.

13. Raffetto JD, Khalil RA. Matrix metalloproteinases and their inhibitors in vascular remodeling and vascular disease. Biochem Pharmacol. 2008;75:346-359.

14. Braca A, Tommasi ND, Bari LD, Pizza C, Politi M, Morelli I. Antioxidant principles from Bauhinia terapotensis. J Nat Prod. 2001;64: 892-895.

15. Sroka Z, Cisowski W. Hydrogen peroxide scavenging, antioxidant and anti-radical activity of some phenolic acids. Food Chem Toxicol. $2003 ; 41: 753-758$.

16. Nishimiki M, Rao NA, Yagi K. The occurrence of superoxide anion in the reaction of reduced phenazinemethosulfate and molecular oxygen. Biochem Biophys Res Commun. 1972;46:849-853.

17. Barrantes E, Guinea M. Inhibition of collagenase and metalloproteinases by aloins and aloe gel. Life Sci. 2003;72:843-850.

18. Ude C, Manfred SZ, Mario W. Ginkgo biloba extracts: a review of the pharmacokinetic of the active ingredients. Clin Pharmacokinet. 2013;52:727-749.

19. Noda Y, Kaneyuka T, Mori A, et al. Antioxidant activities of pomegranate fruit extract and its anthocyanidins: delphinidin, cyanidin and pelargonidin. J Agric Food Chem. 2002;50:166-171.

20. Singh RP, Chidambara MKN, Jayaprakasha GK. Studies on the antioxidant activity of pomegranate (Punica granatum) peel and seed extracts using in vitro models. J Agric Food Chem. 2002;50:81-86.

21. Butt MS, Nazir A, Sultan MT, Schroën K. Nature's functional tonic. Trends Food Sci Technol. 2008;19:505-512.

22. Chung KO, Kim BY, Lee MH, et al. In-vitro and in-vivo antiinflammatory effect of oxyresveratrol from Morus alba L. J Pharm Pharmacol. 2003;55:1695-1700.

23. Khan MA, Rahman AA, Islam S, et al. A comparative study on the antioxidant activity of methanolic extracts from different parts of Morus alba L. (Moraceae). BMC Res Notes. 2013;6:2-9.

24. Debib A, Tir-touil A, Mothana RA, Meddah B, Sonnet P. Phenolic content, antioxidant and antimicrobial activities of two fruit varieties of Algerian Ficus carica L. J Food Biotechnol. 2014;38:207-215. 
25. Yang X-M, Yu W, Ou Z-P, Ma H-L, Liu W-M, Ji X-L. Antioxidant and immunity activity of water extract and crude polysaccharide from Ficus carica L. fruit. Plant Foods Human Nutr. 2009;64:167-173.

26. Jain DP, Pancholi SS, Rakesh P. Synergistic antioxidant activity of green tea with some herbs. J Adv Pharm Tech Res. 2011;3:177-183.

27. Fisher GJ, Voorhees JJ. Molecular mechanisms of photo aging and its prevention by retinoic acid: ultraviolet irradiation induces MAP kinase signal transduction cascades that induce AP-1-regulated matrix metalloproteinases that degrade human skin in vivo. J Invest Dermatol Symp Proc. 1998;3:61-68.

28. Seo UK, Lee YJ, Kim JK, et al. Large scale and effective screening of Korean medicinal plants for inhibitory activity on matrix metalloproteinase-9. J Ethnopharmacol. 2005;97:101-106.
29. Thring TS, Hili P, Naughton DP. Anticollagenase, antielastase and antioxidant activities of extracts from 21 plants. BMC Complement Altern Med. 2009;9:1-11.

30. Madhan B, Krishnamoorthy G, Rao JR, Nair BU. Role of green tea polyphenols in the inhibition of collagenolytic activity by collagenase. Int J Biol Macromol. 2007;41:16-22.

31. Tanaka T, Okada T, Konishi H, Tsuji T. The effect of reactive oxygen species on the biosynthesis of collagen and glycosaminoglycans in cultures human dermal fibroblasts. Arch Dermatol Res. 1993;285:352-255.

32. Fisher GJ, Datta S, Talwar HS, et al. Molecular basis of sun-induced premature ageing and retinoid antagonism. Nature.1996;379:335-339.

\section{Publish your work in this journal}

Clinical, Cosmetic and Investigational Dermatology is an international, peer-reviewed, open access, online journal that focuses on the latest clinical and experimental research in all aspects of skin disease and cosmetic interventions. All areas of dermatology will be covered; contributions will be welcomed from all clinicians and basic science researchers globally. This journal is indexed on CAS. The manuscript management system is completely online and includes a very quick and fair peer-review system, which is all easy to use. Visit http://www.dovepress.com/testimonials.php to read real quotes from published authors.

Submit your manuscript here: http://www.dovepress.com/clinical-cosmetic-and-investigational-dermatology-journal 